\title{
Promoting the Fine Management of Finance and Accounting and Improving the Ability to Create Value
}

\author{
Yang Liqun \\ Jiangsu Vocational Institute of Commerce, Nanjing, Jiangsu, 210000
}

Keywords: Accounting, Fine management, Value, Creativity

\begin{abstract}
At present, due to the gradual increase of small and medium-sized enterprises in the country, potential market competitiveness is brought. If enterprises want to win the competition in huge market, they need to constantly improve the rules and regulations among the various departments of an enterprise, meanwhile pay more attention to the management of an enterprise's financial department. Accounting is the core of the enterprise, the flow of enterprise funds is presented by the accounting department, so the accounting department in charge of the economic lifeline of the enterprise, can promote the further development of enterprises and achieve their own strategic goals. Enterprises should start from the subtle aspects of strengthening the management of financial accounting, effectively improve the management level and efficiency of the accounting department, and enhance the ability of enterprises to create value. This article will analyze and explore how to promote the fine management of the financial accounting, so as to better enhance the value of creativity and so on.
\end{abstract}

\section{Introduction}

Enhancing the fine management of accounting is a new historical stage for a company to carry out reform and development. After the enterprises have comprehensively sorted out their own shortcomings, it is a top priority for enterprises to make important improvements in accounting management. Nowadays, the management of the financial accounting needs to be meticulously meticulous. Its positive role and value are still remarkable. In particular, it can create value for itself and promote the steady and sustained development of various businesses. Based on the analysis of the connotation of the refined management of the finance and accounting, this article starts with the significance of the refined management of the finance and accounting, and focuses on the ways and means of the refined management of the finance to enhance the value creation.

\section{Financial precision management to enhance the value of the ability to create a comprehensive factor}

The key to the sound development of an enterprise during the management process is also the key for the enterprise staff to work according to the rules and regulations. In order to expand the competition and influence of enterprises in the market, enterprises vigorously carry out the management activities of fine accounting and accounting, so that the business scale of the entire enterprise is gradually strengthened, the enthusiasm of staff is steadily increasing, and the profitability of enterprises is also increasing year by year. However, with the increasing social demands on the resources of enterprises and the control of external factors such as the increasingly powerful competitors, the sustainable development of the epitaxial growth mode by resources is getting lower and lower. Therefore, enterprises should consider opening up a sustainable development path from inside to further enhance the value creation ability of enterprises. Continuously improve the management of the refined financial accounting, the maximum level to stimulate the creation of staff positions, continue to optimize the allocation of resources, and constantly broaden the value creation of space.

Fine management of accounting is based on the development of the entire enterprise gradually established, which is to promote the standardization of enterprise management is an important 
measure and task, to continue to strengthen the scientific and rational accounting department is to enhance the basis for the creation of value, at the same time, it also helps and promotes the development of other businesses in the enterprise.

\section{Fine management of accounting to enhance the value of creating meaning}

To continuously and steadily improve the enterprise's value creation ability, it is necessary to get out of an internal development path. The continuous performance management mode can promote employees of all departments to exert their potential and create greater value for the enterprise. Fine management of accounting needs enterprises to make a detailed plan, promote savings and increase expenditure on all projects, and effectively control the resources invested in and create value.

\section{Fine management of accounting and to enhance the value of creative ability to explore}

The management of the fine accounting of the enterprise is not achieved by virtue of effort, but requires the joint efforts of the enterprise leaders and employees to formulate plans and effectively implement them so that the parties can achieve it. In promoting the fine management of the financial accounting, as well as to enhance the value of the ability to create the development of enterprises needs to put forward a continuous update and improve the path.

1) Quantify management details. Enterprises should continue to cultivate the awareness of staff in all departments to quantify the details and continue to create details of the quantitative system. In the normal work and management process, the real from every detail, every branch, as well as staff from each post can actually act in accordance with the rules and regulations can strictly regulate every detail, so that the operation of the accounting business continuously standardized and modernized, without leaving any business flaws and mistakes. The grassroots staff is the main body of enterprise fine management, but also the effective implementation of the specific accounting work, first of all, to enhance staff performance of the work and tasks of the financial management are the core of fine management. In the process of work, any one level problems, will affect the smooth realization of the ultimate interests. Therefore, employees in each position have an important mission and mission. They must strictly regulate themselves in their work, strictly require themselves and strictly abide by the various systems, and closely integrate their work with the careful management of accounting and finance. Dependable, positive job tasks completed.

2) Optimization of accounting supervision. With the development of modern science and technology, most of the accounting and accounting work of Chinese enterprises are implemented by computer. Therefore, to optimize the information technology and improve the fine management of the accounting, the accounting department should improve the accounting information management system, apply the information technology and improve the work efficiency, to ensure the accuracy of the work. In addition, we must improve the financial sector mechanism. According to the current situation of the accounting department, business leaders should formulate a series of new rules and regulations that are in line with the working conditions and management mode of existing employees, effectively blocking all omissions and loopholes. Through high-tech means, the budget department of finance and accounting departments and a series of work to strictly monitor and control, refine the duties of various positions, improve the internal management system for the financial management of fine problems in scientific and rational circumvention, and effectively promote the management level of the entire enterprise to enhance. The last is to increase the creative ability of enterprises. To strengthen the management of the fine accounting, that is, to strengthen the process of accounting management and operational mechanism, and establishes a more efficient financial management system, so that financial management can be effectively improved to promote the competitiveness of enterprises and enhance the value of creativity.

3) Improve the management concept. For the management concept of the enterprise accounting department to change with the development of the times, business leaders should fully recognize the important role of the enterprise finance and delicacy management, leaders also have to play a leading role in the management of the refinement of the accounting and promote the formation of a 
positive and good atmosphere throughout the enterprise. In the work, the accounting department should be "meticulous and pragmatic" as a management philosophy, and keep it in mind, and let every employee can keep this in mind, and apply this idea to the actual work. Enterprises also need to strengthen the ranks of the accounting department. Through the selection of outstanding financial management personnel to enhance the professional quality of the accounting department staff in the accounting department to achieve meticulous management principles, we must first be strict management, and secondly, we should regularly carry out business and moral quality training on the staff in the accounting department, and in a period of time, the organization of accounting department staff to conduct business exams, and examination results in the entire enterprise for publicity, for those who have poor grades or unqualified, criticism and warning, and re-learn the examination, to praise and give encouragement to those with outstanding achievements, we can even promote the active and serious work of all employees even by raising salaries and material rewards, resulting in the improvement of the overall quality of the entire accounting and accounting team.

4) Strengthen the accounting department's accounting awareness. Accounting managers must first establish a rigorous scientific attitude and pragmatic spirit, in their work to their own high standards and strict requirements, and often to their own work objectives and tasks, and constantly improve themselves and improve accounting standards and ability, conscientiously do a good job accounting and management. Business leaders in the accounting department to vigorously promote the issue of resource allocation and accounting essentials, so that the accounting and accounting can be maximized to play, the financial management of fine management pattern can penetrate into the hearts of each staff member. Moreover, the enterprises should standardize the revenue and expenditure of the accounting department, clearly grasp the problems of the positioning of interest rates and capital controls, reduce the risk of the enterprises and maximize the value creation ability of the refined management of the financial and accounting departments. Enterprises should also follow the financial management requirements of the refinement, through the planning, control, supervision and other methods to further strengthen performance management, improve the accounting content of accounting, improve operating costs, and promote the healthy and stable development of the entire enterprise.

\section{Financial accounting refinement management to enhance the ability to create value}

How to improve the value creation ability through the fine management of the financial accounting system is a problem that the small, medium and large-sized enterprises need to consider in China. However, I would like to put forward a series of solutions to this problem for further reference.

1) Do a good job of financial management, the key refinement. In the accounting department to establish the responsibility system of leadership to establish the accounting department and other departments and the coordination of all levels of employees in the work and business contacts and the accounting department of the various staff to work out tasks so that everyone in their own jobs Have their own post, to play their own abilities. For the accounting and management departments to implement regulatory functions, one is to continue to implement the management and control platform needs, and promote the allocation of resources can be effectively implemented to various platforms. Second, we must grasp the accounting policies and management programs, give guidance to grassroots units, and improve the working attitude and efficiency of grassroots workers, and let everyone work together to implement every measure.

2) Steady and continuous improvement of management. Enterprises want to change the management style of the accounting department, to convey updated management experience, but to change the management system is not a one-stop thing, need to penetrate and implement through the daily work bit by bit. At the same time, the fine management of the accounting department is also a long-term task, with the social changes and the continuous development of enterprises, financial management will refine the management approach will change, in the daily work, staff members should constantly communicate and discuss together, and constantly summarize and 
reflect on unreasonable aspects of the work process, and constantly push forward the management of fine accounting.

3) Do a good job accounting and financial management process. First of all, companies should highlight the ability of business accounting control. According to the business development trend of the accounting department at this stage, the requirements for the supervision and administration of the financial accounting system are improved and optimized, and the enterprises can effectively control their business posts and enable the leaders to fulfill their responsibilities; Second, in the internal management system of the enterprise finance and accounting, we should take the principle and policy of "business management and job execution well-founded", carry out strict management and supervision on various tasks and tasks that are prone to potential risks in the work of the finance and accounting department and pay attention to features that are easy to operate and practical in the course of carrying out their tasks; Finally, we should effectively strengthen the cost control methods In the "12th Five-Year Plan", it has been shown that perfecting the management of finance and accounting is to increase the cost and budget management, and to achieve the change of the financial management function through comprehensive budget management. First, it is necessary to increase the control over costs and monitor the costs on a regular basis so as to gradually reduce the differences between costs and benefits and achieve the assistance and cooperation of both; Secondly, to improve the cost control and control so that cost control and financial budget can be effectively combined. The current expenses are classified and fixed again according to fixed costs and staff costs, so as to ensure that the maximum cost and business development can be achieved consistent; Third, to strengthen the financial control ability, take the initiative management mode in the financial department, adopt a standardized budget management process, analyze according to the specific data of the budget, improve the budget assessment system and evaluation work, make the financial budget as accurate as possible, for the enterprise's capital investment and spending a more clear range.

4) Implementation of refined management requirements. Enterprises should improve the supervision and management system of accounting as soon as possible and determine the regulatory route and policy. The supervisory team and personnel must be representative persons or leaders in the enterprise, which can have a positive impact on the staff in the accounting department. At the same time, we must also supervise and inspect the enterprises' accounting department staff. Supervisors should supervise the daily work items of the accounting department, the accounting operations of the basic institutions and the handling of the key business contents, and according to the accounting remote monitoring system for real-time supervision and irregular random review. After monitoring, the work of the accounting department to promote and implement the project for the problems and responsible persons should promptly correct the problem, effectively solve the problem of practical management of fine accounting management, effectively correct the potential hidden dangers and problems, improve the quality of corporate financial management and fine work level and efficiency.

\section{Conclusion}

To sum up, this article analyzes and describes the impact of the refined management of accounting on the value creation ability of enterprises from four aspects. The author believes that under the background of today's era, the competitive pressures of enterprises are gradually increasing. In order to be in a favorable position in market competition, relevant management cannot be lacking. The financial management of the fine management of the accounting department of work quality control and thinking of management models and methods has certain advantages, to control and improve the financial sector's business operations. The fine management of finance is not accomplished in a single step and takes a long time to reform and perfect it. Enterprises should not only manage the construction of elaborate management but also clarify the procedures and standards of meticulous work and keep the standards in mind, apply to future work. In the enterprise's fine management of financial accounting, business leaders must uphold the scientific process of clear process, improve the system, and determine job responsibilities and other scientific 
and rational approach, prompting the completion of the enterprise's financial management and meticulous management objectives, while enhancing the enterprise's value-creating ability.

\section{References}

[1] Zhou Jianping. Promote the standardization of trade union financial management to enhance trade union financial management level [J]. China Trade Unions .2010 (03)

[2] Wu Juan. Application of ERP information system in the improvement of enterprise accounting and financial management [J]. Journal of Jiangsu Science and Technology.2017 (10)

[3] Wu Jicheng. Reflections on the Integration of Management Accounting and Financial Management - From the Perspective of Monetary Value Attributes and Enterprise Value Management [J]. Fiscal Supervision .2016 (02)

[4] Yu Chuan. Deepening the Reform and Optimizing Management, Strengthening and Regulating the All-round Achievement of the Objectives and Tasks of 2004 Railway Accounting Work [J]. Railway Transport and Economy, 2004 (03)

[5] Hong Jie. Taking the New Accounting System as an Opportunity to Construct Hospital Financial Management Platform[J]. Finance and Economics (Academic Edition) .2016 (20)

About the author: Yang Liqun, female (1978.11-), Nanjing, Jiangsu, lecturer, master's degree, research direction: financial accounting. 